\title{
PRELIMINARY STUDY IN CHILDREN WITH AUTISTIC SAVANT SYNDROME
}

\author{
Vijay Kumar Sah
}

\begin{abstract}
Background: Savant syndrome, characterized by remarkable islands of mental ability in otherwise mentally handicapped persons, may occur in autistic as well as non autistic individuals. Overall, approximately $10 \%$ of autistic persons exhibit savant abilities. Savant skills are typically confined to five areas: art, music, calendar calculating, mathematics and mechanical/spatial skills.

Methods: Data taken from the third affiliated hospital of Sun Yat- Sen university from December 09, 2008 to September 08, 2009. We have analyzed 885 cases, among them 725 were with autistic disorder and 160 were of Mental retardation. Total subjects enrolled were altogether 48; Male 45, Female 3 with mean and SD of age $7.08 \pm 2.31$ years. Number of savant skills in children group includes 11 Autism, 10 HFA, 26 AS, 1 MR.

Results: Approximately one in thirteen (7\%) of children with autistic disorder had savant skills in our study. Approximately less than $1 \%$ of children with developmental disability, mental retardation had savant skills in our study. Overall, many more males showed some form of savant skill. Artistic skill is one of the most common savant skills seen in autistic children. The socioeconomic status of the parents of autistic children was relatively high.

Conclusions: We thus conclude that autism (or autistic traits) and savant skills are inextricably linked and we should therefore look to autism in our quest to solve the puzzle of the savant syndrome.
\end{abstract}

Key words: Autistic, Savant syndrome, talent, intelligence.

\section{Background}

The term "idiot-savant" was first used by Down (1887) to describe intellectually impaired individuals with contrasting outstanding abilities ${ }^{1}$. Savant syndrome, characterized by remarkable islands of mental ability in otherwise mentally handicapped persons, may occur in autistic as well as non autistic individuals. Autism spectrum disorders (ASD) are neurodevelopmental disorders defined by deficits in social reciprocity, communication, and by unusual restricted, repetitive behaviors. Overall, approximately $10 \%$ of autistic persons exhibit savant abilities; roughly $50 \%$ of those with savant syndrome have autism, and the remaining $50 \%$ have other forms of developmental disability. Savant skills are typically confined to five areas: art, music, calendar calculating, mathematics and mechanical/spatial skills.

\section{Methods}

This is a Retrospective study of Savant skills in autistic children. Patients enrolled in this study include patients seen in outpatient department of child developmental and 
behavioral division, the third affiliated hospital of Sun Yat- Sen university from December 09, 2008 to September 08, 2009. Of all the 885 cases, 725 patients were with autistic disorder whereas 160 had mental retardation. Of all those autistic and mental retarded children, 48 subjects had savant skills, with mean and SD of age $7.08 \pm 2.31$ years. Children with less than two and half years old were not included in our study.

The most common savant abilities are called Splinter skills: These include behaviors such as obsessive preoccupation with, and memorization of music and sports trivia, license plate number, map, historical facts etc.

Talented savants are those persons in whom musical, artistic, mathematical or other special skills are more prominent and highly honed, usually within an area of single expertise, and are very conspicuous when viewed against their overall handicap.

Prodigious savant is reserved for those very rare persons in this already uncommon condition where the special skills or ability is so outstanding.

Specific areas of Savant skill - only about five general areas of expertise: Music, Artistic talent, Lightning calculating or other mathematical skills, Mechanical ability, Calendar calculating, Other Skills:-unusual language (polyglot) skills, outstanding knowledge in specific fields such as statistics, map, traffic route map, history or navigation, to name a few.

The collected data were first recorded in Microsoft Excel 2007. With the help of Microsoft Excel 2007, different diagrams were drawn to give the picture of the proportion of autistic population, sex difference, and educational background, proportion of savant skills as well as socioeconomic status of their parents. SPSS 16.0 (SPSS Inc., Chicago, IL) was used during the analysis. All the variables are expressed as mean \pm standard deviation.

\section{Results:}

\section{Characteristics of autistic child}

We have analyzed 885 cases, among them 725 were with autistic disorder (Autism 542, HFA 63, AS 120) and 160 were of Mental retardation. Number of savant skills in children group includes 11 Autism, 10 HFA, $26 \mathrm{AS}, 1 \mathrm{MR}$; that is one in thirteen $(7 \%)$ of children with autistic disorder had savant skills whereas less than $1 \%$ of children with developmental disability, mental retardation had those skills in our study as shown in fig 1 and table 1.

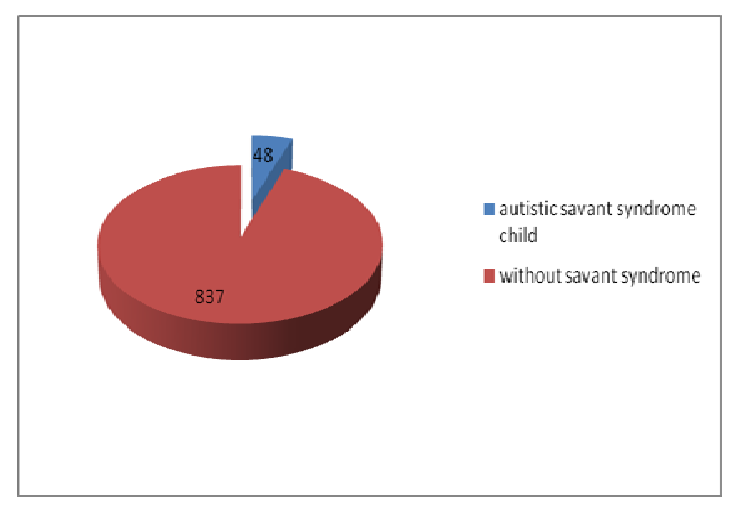

Fig.1 Pie chart showing the proportion of autistic savant skills children in our study

\begin{tabular}{lll}
\hline $\begin{array}{c}\text { Disease of savant } \\
\text { children }\end{array}$ & Number \\
\hline Autism & 11 & \\
HFA & 10 & \\
AS & 26 \\
MR & 1 & \\
\hline
\end{tabular}

Table 1: Number of savant skills children group

Out of total 48 cases; 45 were males and 3 females, with male: female ratio for cognitive skill was 15: 1 
Education obtained by savant skills children group includes, 34 primary school (70.83\%), 13 kindergarten (27.08\%), 1 middle school $(2.08 \%)$ as shown in fig 2.

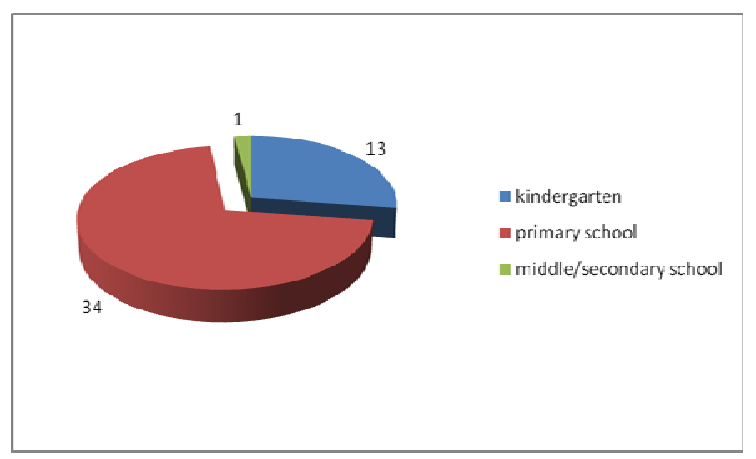

Fig.2: Education obtained by savant skills children in this study

\section{Savant skills of children reported as by parents and teacher:}

Of those 48 savant skilled child, parent reported $45(93.75 \%)$ of their children has those skills compared to teacher who only reported $32(66.66 \%)$ cases had savant skills

\section{Number of Savant skills found in children in our study:}

In total, 48 individual enrolled in this study were having one or more savant skills. There were 27 artistic, 20 mechanical abilities, 13 music, 12 lightning calculating, 12 mathematical skills, 2 calendar calculation skills and other skills( 8 license plates number, 5 history, 1 sport, 16 map, 13 language skills) as shown in fig 3.

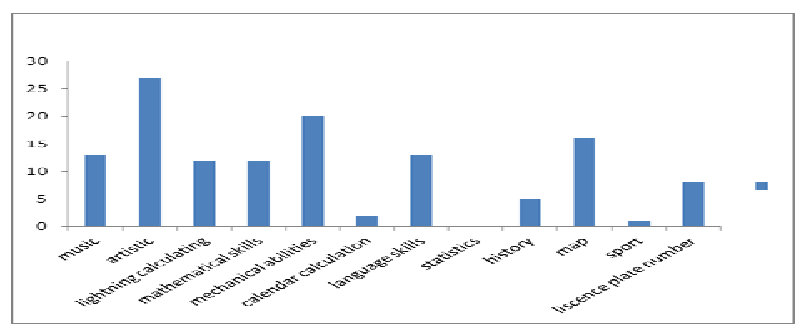

Fig. 3: Savant skills of the children in our study
Several individuals have multiple savant skills. Some common combinations of two different skills are artistic and mechanical abilities found in 10 cases, artistic and language skills in 8 cases, music and artistic in 7, music and mechanical abilities in 7, artistic and lightning calculation in 7, artistic and map in 7, mechanical abilities and language skills in 7 cases etc which is shown in fig 4.

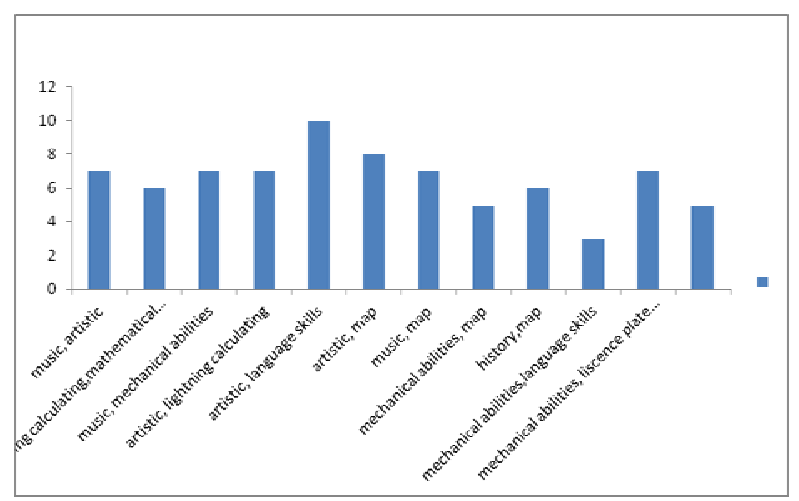

Fig.4: Diagram showing some common savant skills combination

4. The relation of autistic savant skills children with respect to their parents Socioeconomic Status (SES)

Parent educational status of university level or higher in autism children was 54.5\% but in case of HFA children was $80 \%$ whereas 88.5\% of AS children's parent had studied university or more than that which is shown in fig 5 .

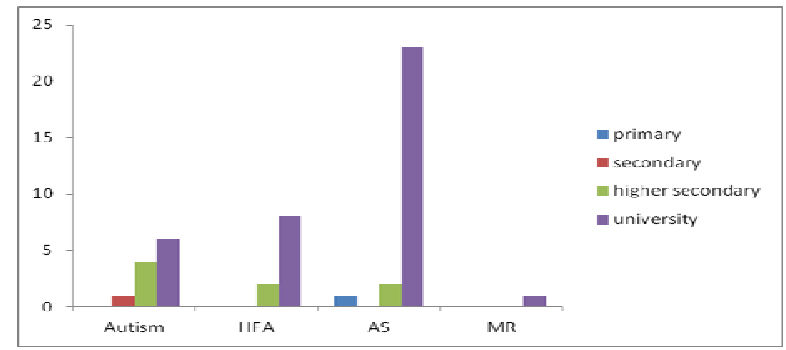

Fig. 5: Children group and their parent education While concerning about the economic status; $81.8 \%$ of autism children, $90 \%$ of HFA children and $84.6 \%$ of AS children's parents 
had good or very good economy status as shown in fig 6 .

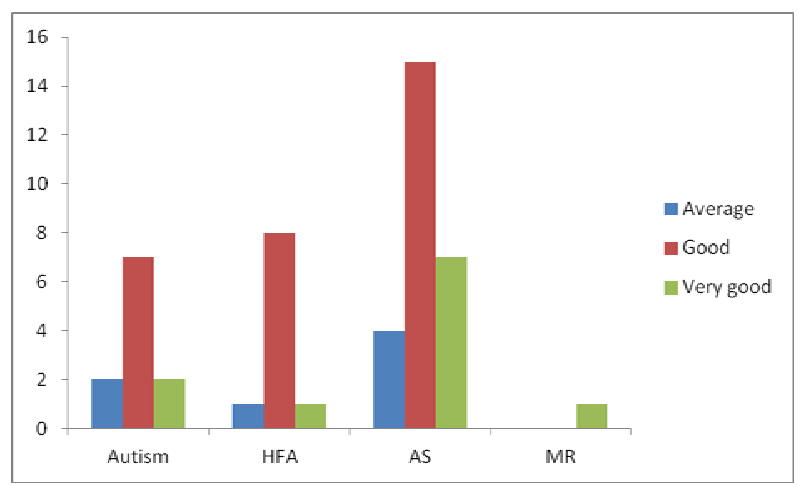

Fig. 6: Family economy in different children groups

\subsection{Distribution of Savant skills children in Autistic population}

Approximately, one in thirteen (7\%) of children with autistic disorder had savant skills and less than $1 \%$ of children with developmental disability, mental retardation had savant skills in our study. Whereas similar study done outside China showed that approximately one in ten (10\%) of persons with autistic disorder (i.e., Autism, HFA, AS) have some savant skills. In other forms of developmental disability, mental retardation or brain injury, savant skills occur in less than 1\% of such persons (approximately 1: 2000 in persons with mental retardation) $)^{2,3}$. It can also not be neglected that as the study is carried out in different geographic regions and in different races, there can be difference in development of these skills.

SEX DIFFERENCES: Greater number of autistic males had savant skills compared to female in our study, male: female ratio being 15: 1 . Similar study done outside China also showed four to six times increased ratio in males than females. Research by Geschwind and Galaburda, demonstrated in the developing human fetus the left hemisphere of the brain always completes its development later than the right hemisphere resulting in longer duration of exposure of left hemisphere compared to the right for any kind of brain insult or injury. Such damage can be caused by circulating testosterone, which in male fetus, reaches very high levels, and can be neurotoxic too. This testosterone mediated developmental injury, causing left hemisphere brain damage before birth in males may account in some other forms of CNS injury such as stuttering, dyslexia, hyperactivity, other learning disabilities and autistic disorder itself $^{2}$.

\subsection{Savant skills found in children in our study}

In our study, 48(6.62\%) individual enrolled were having one or more savant skills. Of those with reported skills, the most common were 27 artistic(56.26\%), 20 mechanical abilities(41.66\%), 13 music(27.08\%), 12 lightning calculating (25\%), 12 mathematical skills (25\%), 2 calendar calculation skills (4.16\%) and other skills (8 license plates number, 5 history, 1 sport, 16 map, 13 language skills). Higher proportion of artistic skills seen may be due to the intense focus on and ability to remember visual detail in these children. Anatomic substrate for artistic savant syndrome may involve loss of function in the left temporal lobe with enhanced function of the posterior neocortex ${ }^{4}$.

\subsubsection{Neurologically mediated multi- factor model of Savant skills}

Brain-based factors include compensatory right-hemisphere functioning after lefthemisphere damage and reliance upon lower level procedural memory due to damage to higher level (e.g., semantic) memory circuitry ${ }^{3}$.

Brink notes that the left brain generally governs the use of language, mathematical computation and other orderly conceptual. The right brain is generally superior in tasks involving spatial relationships, activities 
involving visualization and movement and skills such as mechanical ability ${ }^{5}$. Mechanical abilities seen may be due to the right brain is generally superior in tasks involving spatial relationships, activities involving visualization and movement ${ }^{5}$. He notes that in the case of Mr. A., performance on test of language skills was very low, whereas scores in testing of mechanical ability- right brain function- were very high ${ }^{6}$. Musical ability was the most frequently reported skill followed by memory. More recent data further address the question of unexploited musical potential in children with autism. In this study (Heaton et al. 2008a), high- and low-functioning children with autism completed tests of pitch discrimination and memory ${ }^{7}$. Miller et al. (1998) conclude that 'loss of function in the left anterior temporal lobe may lead to "paradoxical functional facilitation" of musical skills 8 .

\subsection{Savant skills of children reported by parents and teachers}

Among 48 savant skills child, 45(93.75\%) were informed as savant skills by parents and only 32(66.66\%) were informed as savant skills by teachers. The higher proportion reported by the parents can be due to the fact that parents spend more time with their children compared to the teachers. Teachers look the children in mass and they can often neglect those talents shown by the child during the specific period in the school whereas parents often take care of any important actions taken by their child.

\subsection{Study of autistic savant skills children with respect to their parents Socioeconomic Status (SES)}

Parent Educational Status: Education status of the parents with university level in autism children was $54.5 \%$. In case of HFA children, parent education with university level was $80 \%$. But in case of AS children, parent education with university level was even higher (88.5\%). It may be due to environmental components that do play a factor, genetic components, and opportunities etc.

Parent Economy Status: 81.8\% of parents of autism children had good or very good economy status. In case of HFA children, $90 \%$ of their parents had good or very good economy status. Whereas, $84.6 \%$ of parents of AS had good or very good economy status.

Maenner M, Arneson CL, Durkin Ms has reported that ,using educational attainment as an indicator of socioeconomic status, autism spectrum disorder prevalence increased from 2.6 per 1000 in the lowest to 6.8 per 1000 in the highest education quintile. The prevalence ratio for the highest to lowest education quintile was 2.6:1 (95\% confidence interval: 1.6, 4.5). Using median household income as an indicator of socioeconomic status produced similar results. Autism spectrum disorder prevalence is positively associated with socioeconomic status based on populationbased surveillance in Wisconsin. (Maenner M, Arneson CL, Durkin Ms). Department of Population Health Sciences, University of Wisconsin School of Medicine and Public Health, Madison, WI 53726, USA."9 . Second, it has been suggested that the tendency for an association between higher SES and autism might be the result of professional perception as it relates to the disability. For instance, in a study conducted by Cuccaro et al. (1996), it was found that children from families of higher SES were associated with a greater likelihood of a diagnosis of autistic disorder while children from families of lower SES were having their developmental and behavioral abnormalities characterized as cultural deprivation ${ }^{10}$. 


\section{Conclusion}

The socioeconomic status of the parents of autistic children was found to be relatively high and autistic savant skills are more frequently seen in male gender, with artistic skill being one of the most common savant skills seen in autistic children. These skilled children need as much training and encouragement as is given to any individual with other groups so that autistic population can help in detailed processing, mathematics, engineering, design and so on.

\section{References}

1. Down, J. L. $\mathbf{1 8 8 7}$ On some of the mental affections of childhood and youth. London, UK: Churchill.

2. Treffert, D. 2000 Extraordinary people: understanding savant syndrome. New York, NY: Ballantine Books.

3. Treffert, D. 1989 Extraordinary people: understanding 'Idiot Savants'. New York, NY: Harper \& Row.

4. Hou C, Miller BL, Cummings JL, Goldberg M, Mychack P, Bottino V, Benson DF. Autistic savants. [correction of artistic] Department of Neurology, Washington University, St. Louis, Missouri, USA. PMID: 10645734

5. Brink Am- Idiot savant with unusual mechanical ability: an organic explanation J. Psychiatry.1980; 137: 250-251
6. Hoffman, E., and Reeves, R.: An idiot savant with unusual mechanical ability. Am. J. Psychiatry 136:713-14,1979.

7. Heaton, P., Williams, K., Cummins, O.\& Happe', F. 2008a Autism and pitch processing splinter skills: a group and sub-group analysis. Autism 12, 21-37. (doi:10.1177/ 1362361307085270)

8. Miller BL, Cummings J, Mishkin F, Boone K, Prince F, Ponton M, Cotman C. Emergence of artistic talent in frontotemporal dementia. Neurology 1998;51:978-982.

9. Maenner M, Arneson CL, Durkin Ms.Autism spectrum disorder prevalence is positively associated with socioeconomic status based on population-based surveillance in Wisconsin. Department of Population Health Sciences, University of Wisconsin School of Medicine and Public Health, Madison, WI 53726, USA.).

10. Cuccaro, M. L., Wright, H. H., Rownd, C.V., Abramson, R.K., Waller, J., \& Fender, D. (1996). Brief report: professional perceptions of children with developmental difficulties: the influence of race and socioeconomic status. Journal of Autism Development Disorder, 16(4), 461-469.

Corresponding Author: Dr. Vijay Kumar Sah, Lecturer, Nobel Medical College, department of pediatrics, biratnagar, email:drvks18@gmail.com Zhou Xiao Bing Professor, third affiliated hospital of Sun Yat Sen university 